\title{
Which Of The Recommended Home Exercises For Low Back Pain Is Easier To Learn And Remember?
}

serap satis ( $\square$ mdseraps@gmail.com )

Harran University School of Medicine

\section{Research Article}

Keywords: Low back pain, home exercise program, time, remember, repetition

Posted Date: June 21st, 2021

DOI: https://doi.org/10.21203/rs.3.rs-611188/v1

License: (c) (i) This work is licensed under a Creative Commons Attribution 4.0 International License. Read Full License 


\section{Abstract}

\section{Background}

We evaluated the learning time and remember of the exercises which given the home exercise program low back pain patients.

\section{Methods}

The study included patients aged 20-65 years who had been suffering from a mechanical low back pain. All patients were informed about the study and an informed consent was obtained from each of them. A socio-demographic form probing age, gender, and educational status was filled in by the patients. All the patients were taught five exercises which were aimed at increasing trunk and lower extremity muscle length, strength, and endurance by the same physiotherapist and the exercises were repeated by the patients in the presence of the physiotherapist until they were performed fully and appropriately. In the meantime, total number of repetitions and the duration of learning the exercises (seconds) were noted for each patient. Patients were instructed to perform these exercises for 15 days with 10 sets a day. On the 15-day follow-up session, patients were asked to perform the assigned exercises and those who performed them correctly were recorded as "remembering".

\section{Results}

The patients learned the hamstring stretch, lumbar stretch, and flexor stretch in a shorter period and learned the hamstring stretch with fewer repetitions compared to other exercises. Additionally, lumbar stretch was the most remembered exercise.

\section{Discussion}

We suggest that instead of giving patients multiple complex exercises, patient-specific exercises that can be easily learned and performed without forgetting can be selected and thus lumbar stretch is a suitable option for this purpose.

\section{Introduction}

Therapeutic exercise is defined as bodily movement prescribed to correct an impairment, improve musculoskeletal function, or maintain an optimal state of well-being. The importance of exercise in low back pain treatment has increased over recent years and this importance was first emphasized in a study conducted in 1964 [1].

Low back pain, peaks between the ages of $40-80$ that is a common health problem [2]. Common drugs prescribed for the pharmacological treatment of low back pain include nonsteroidal anti-inflammatory drugs, muscle relaxants, opioids, benzodiazepines, antidepressants, acetaminophen, systemic 
corticosteroids and pregabalin or gabapentin, Therapeutic exercise is a primary non-pharmacological treatment [3]. Moreover, it speeds up recovery and facilitates early return to work [4].

Therapeutic exercises give as a home exercise program or as a component of physical therapy. Often, patients find it difficult to understand and remember the exercises $[5,6]$. Expectedly, exercises do not fully learn and remember difficult to perform. That there are many factors that affect learning and remembering. Although, there have been many studies on exercise efficiency and compliance, to our knowledge, there has been no study investigating the duration of learning home exercise programs and to what extent these programs correctly remember by patients assigned to perform home exercises.

The aim of this study was to analyze the duration of learning and the extent of remembering the exercises in patients assigned to perform home exercises and to compare these parameters with patients' educational status and age in order to help develop patient-based strategies in exercise training.

\section{Materials And Methods}

In this study, all methods were performed in accordance with the relevant guidelines and regulations. The Ethics Committee of Harran University approved this study. Written informed consent was obtained from all the participants.

The study included patients aged 20-65 years who had been suffering from a mechanical low back pain for at least 12 weeks. Patients with vision, hearing, comprehension problems, neurological and orthopedic deficits in the lower extremities excluded from the study. All patients informed about the study and an informed consent obtained from each of them. The patients filled in a socio-demographic form probing age, gender, and educational status. Patients divided into three groups according to their educational status; (i) lower than high school level, (ii) high school level, and (iii) university level. All the patients were taught five exercises which were aimed at increasing trunk and lower extremity muscle length, strength, and endurance by the same physiotherapist and the exercises were repeated by the patients in the presence of the physiotherapist until they were performed fully and appropriately. In the meantime, total number of repetitions and the duration of learning the exercises (seconds) were noted for each patient. Patients instructed to perform these exercises for 15 days with 10 sets a day. On the 15-day follow-up session, patients asked to perform the assigned exercises and those who performed them correctly were recorded as "remembering". On the same day, the total number of repetitions made and the total duration of time, (seconds) spent for learning the exercises and the extent of remembering these exercises recorded for each patient.

\section{Exercises}

Hamstring Stretch reduces the load on the disc and paraspinal muscles by relaxing the hamstrings. When one knee is in flexion and the other leg is in extension, the subject attempts to touch the tip of the toe of 
the extended leg with the hand. When tension experience in the hamstrings, they are loosened and the same procedure is repeated.

Anterior Pelvic Tilt strengthens the back muscles. The subject lies on his/her back with the knees in flexion. The pelvic bone is lift upwards by contracting the gluteus muscle. After waiting for five seconds, the subject returns to the initial state.

Posterior Pelvic Tilt strengthens the abdominal and gluteal muscles, resolves muscle spasm, and corrects lordosis. The subject lies on his/her back with the knees and hips in flexion. Abdominal muscles are contract for five seconds and then relax to ground the low back. While the low back is press on the floor, the hips are slightly lift off the ground and then relax.

Lumbar Stretch increases the flexibility by resolving the spasm of the paravertebral muscles. When lying on the back and pulling the knees into the chest with the help of hands, the subject attempts to touch the knees with the forehead.

Flexor Stretch reduces lumbar lordosis. In the supine position, one knee is pull towards the chest while the other leg is press towards the ground.

\section{Results}

The 69 patients comprised 39 (56.5\%) women and 30 (43.5\%) men. No significant difference was found among the three groups with regard to gender distribution $(p=.770)$. Mean age was $46.71 \pm 11.42$ (range, 20-65) years and no significant difference was found among group I, II, and III with regard to mean age $(48.50 \pm 1.77,45.00 \pm 3.03$, and $40.45 \pm 1.66$ years respectively) $(p=.094)$.

Table 1 presents the duration of learning (seconds), number of repetitions, and the extent of remembering for each exercise. The results indicated that the patients learned the hamstring stretch, lumbar stretch, and flexor stretch in a shorter period and learned the hamstring stretch with fewer repetitions compared to other exercises. Additionally, lumbar stretch was the most remembered exercise.

On the 15-day follow-up session, $28.98 \%$ of the patients remembered all the exercises correctly. Table 2 provides the distribution of patients who correctly remembered all the exercises according to gender, age, and educational status. Mean age of patients that remembered all the exercises correctly was significantly lower than that of patients who did not $(p=.000)$. It was also noted that the university graduates remembered all the exercises significantly better than the other patients $(p=.000)$. However, no significant difference was found in terms of gender $(p=.332)$.

Table 3 presents a comparison of patients' duration of learning and their educational status. The comparison indicated that university graduates learned all five exercises in a significantly shorter time compared to other patients ( $p=.004, p=.000, p=.000$, and $p=.004$, respectively). 
A significant difference was found among the three groups with regard to the number of repetitions performed for learning anterior pelvic tilt, posterior pelvic tilt, and flexion stretch $(p=.000, p=.001$, and $p=.006$, respectively). It noted that patients with an educational level lower than high school education learned these exercises with more repetitions (Table 4).

On the 15-day follow-up session, all the university graduates remembered the anterior pelvic tilt, posterior pelvic tilt, and lumbar stretch correctly. Additionally, all the high school graduates remembered lumbar stretch correctly as opposed to $89.5 \%$ of the patients with an educational level lower than high school education. Moreover, lumbar stretch was the most remembered exercise. It was also found that patients with an educational level lower than high school education remembered the anterior pelvic tilt and posterior pelvic tilt significantly less than the other patients ( $p=.001$ and $p=.003$, respectively) (Table 5).

\section{Discussion}

The present study, for the first time in the literature, analyzed the duration of learning and the extent of remembering the exercises in patients assigned to perform home exercises and found that lumbar stretch and flexor stretch learned and remembered in a shorter time compared to other exercises. We also observed that university graduates showed better performance compared to other patients in terms of duration of learning, number of repetitions, and the extent of remembering. Selecting exercises that can be easily understand and perform by the patients is as important as selecting appropriate exercises for each patient.

The choice of exercise for low back pain depends on the preference of the patient and therapist and also on the cost and safety of the exercises [7]. Home exercise programs typically consist of exercises that can be performed by the patients in their social environment. Prior to implementation, patients mostly instructed by a physiotherapist about the number of repetitions and the total duration of the exercise. Sometimes they can be providing with exercise brochures or even audio or video recordings of the exercises [8].

Weakness in the back extensor and flexor muscles reported in patients with low back pain [9]. Accordingly, patient-specific stretching and strengthening exercises constitute the most important part of the treatment. However, only properly performed exercises contribute to the effectiveness of the treatment. The effectiveness of exercise programs in low back pain showed in numerous studies [10, 11]. However, there is little or no data as to which exercise is superior in low back pain. Most of the studies available in the literature have compared stabilization exercises with various types of exercises and have found that all of these exercises reduce pain and that the exercises are not superior to each other [12-17].

Isolated lumbar stabilization exercises showed to have positive effects on pain [18]. Moreover, it showed that isokinetic and standard exercise programs have no superiority over each other [19].

Most of the studies investigating home exercise programs have evaluated patients' compliance rather than the effect of these programs. A previous study evaluated the adherence of the patients to home 
exercise programs and the factors affecting adherence and revealed that $39 \%$ of the patients showed full adherence to home programs and also found a significant relationship between adherence and parameters such as age, environmental motivation, understanding of the exercises, physiotherapist's explanation quality, control and assessment of home exercises by the physiotherapist, and the patient's trust in the physiotherapist [5]. Another study reported that the compliance rate was $9 \%, 73 \%$, and $18 \%$ in patients aged $15-25,26-44$, and 45 years and older, respectively. The authors also noted that fatigue, forgetting or avoiding exercises, not having enough time for the exercises, and believing that exercises are not beneficial had a negative impact on patient compliance [20].

Campbell et al. reported that their patients' initial compliance with the home exercise program decreased over time [21]. In another study investigating compliance with home exercise programs, patients gave three exercises and brochures and the results indicated that there was $71.6 \%$ compliance with the exercises regardless of gender [10]. In contrast, another study found that women showed less compliance with the exercise program compared to men [22]. Despite these conflicting results, we did not observe any difference between the two genders in terms of duration of learning and the extent of remembering.

Rastall et al. compared young and old patients with regard to the capacity for remembering and performing home exercises and suggested that although the elderly forgot the exercises more, the rate of forgetting was also high in young people and thus brochures should given to all patients [6]. In our study, mean age of the patients who did not remember the exercises was higher than that of patients who remembered them correctly, which could be due to the adverse effect of degenerative changes in the brain and neurons caused by age-related decrease in cerebral blood flow on the cognitive functions such as learning, memory, and problem solving. [23]. Based on these findings, we also suggest that patients aged over 50 years should be given longer education and should be provided with visual or auditory support.

Peek et al. reported that only $16.6 \%$ of the patients remembered the exercises correctly [24]. In our study, $28.98 \%$ of the patients remembered all five exercises correctly, whereby the most remembered exercise was lumbar stretch (92.7\%) and the least remembered exercise was anterior pelvic tilt (60.8\%). Accordingly, we suggest that lumbar stretch, which is the most important exercise in terms of relaxing the paravertebral muscles, provides significant relaxation thus; patients should take utmost care to remember this exercise.

Our study limited since the patients' social environment prevented them from exercising, their psychological conditions did not evaluate, and the study had a small sample of patients.

\section{Conclusions}

In conclusion, the results indicated that educational status and age are important factors affecting the duration of learning and the extent of remembering home exercises and that patients had difficulty particularly in learning and remembering the anterior pelvic tilt and posterior pelvic tilt. Additionally, lumbar stretch was the most remembered exercise, mainly because patients experienced greater relaxation after this exercise. 
I suggest that instead of giving patients multiple complex exercises, patient-specific exercises that can be easily learn and perform without forgetting can be select and thus lumbar stretch is a suitable option for this purpose. Additionally, when assigning multiple exercises to patients aged over 50 years, the exercises should be clearly explained by the physiotherapist within a minimum period of 30 seconds with at least 5 repetitions and also audio or video support should be provided.

\section{Declarations}

\section{Ethics approval and consent to participate}

The Ethics Committee of Harran University approved this study. Written informed consent was obtained from all the participants. In this study, all methods were performed in accordance with the relevant guidelines and regulations.

\section{Consent for publication}

Applicable.

\section{Availability of data and material}

The datasets used and/or analysed during the current study available from the corresponding author on reasonable request.

\section{Competing interests}

The author declares that they have no competing interests.

\section{Funding}

The author received no financial and material support.

\section{Author contributions:}

Study design, patient recruitment and assessments, data analysis and interpretation, drafting of manuscript, and review of manuscript for intellectual content: SS

\section{Acknowledgements}


Thanks to Physiotherapist Celal Erdem for her help.

\section{References}

1. Woodhead BH, Fowler JR. The Dynamıc Treatment Of The Low Back Straın Syndrome. Can Med Assoc J. 1964;90(20):1152-1155.

2. Hoy D, Brooks P, Blyth F, Buchbinder R. The Epidemiology of low back pain. Best Pract Res Clin Rheumatol. 2010;24(6):769-781. doi:10.1016/j.berh.2010.10.002.

3. Qaseem A, Wilt TJ, McLean RM, Forciea MA; Clinical Guidelines Committee of the American College of Physicians. Noninvasive Treatments for Acute, Subacute, and Chronic Low Back Pain: A Clinical Practice Guideline From the American College of Physicians. Ann Intern Med. 2017;166(7):514-530.

4. Kamper SJ, Apeldoorn AT, Chiarotto A, et al. Multidisciplinary biopsychosocial rehabilitation for chronic low back pain: Cochrane systematic review and meta-analysis. BMJ. 2015;350:h444.

5. Chan D, Can F, Patients' adherence/compliance to physical therapy home exercises, Fizyoterapi Rehabilitasyon. 2010;21(3):132-139.

6. Rastall M, Brooks K, Klarneta K, Moylan N, Mccloud W, Tracey S, An Investigation into Younger And Older Adults' Memory for Physiotherapy Exercises, Physiotherapy 1999;85:3.

7. Saragiotto BT, Maher CG, Yamato TP, et al. Motor control exercise for chronic non-specific low-back pain. Cochrane Database Syst Rev. 2016;(1):CD012004. Published 2016 Jan 8. doi:10.1002/14651858.CD012004

8. Salik Sengul Y, Kaya N, Yalcinkaya G, Kirmizi M, Kalemci O. The effects of the addition of motor imagery to home exercises on pain, disability and psychosocial parameters in patients undergoing lumbar spinal surgery: A randomized controlled trial. Explore (NY). 2020;\$1550-8307(20)30082-3. doi:10.1016/j.explore.2020.02.001.

9. Bayramoğlu M, Akman MN, Kilinç $S$, et al. Isokinetic measurement of trunk muscle strength in women with chronic low-back pain. American Journal of Physical Medicine \& Rehabilitation. 2001;80(9):650-655.

10. Kolt GS, McEvoy JF. Adherence to rehabilitation in patients with low back pain. Man Ther. 2003;8(2):110-116.

11. Durmus $D$, Unal $M$, Kuru O. How effective is a modified exercise program on its own or with back school in chronic low back pain? A randomized-controlled clinical trial. J Back Musculoskelet Rehabil. 2014;27(4):553-561. doi:10.3233/BMR-140481.

12. Suh JH, Kim H, Jung GP, Ko JY, Ryu JS. The effect of lumbar stabilization and walking exercises on chronic low back pain: A randomized controlled trial. Medicine (Baltimore). 2019;98(26):e16173.

13. Oh YJ, Park SH, Lee MM. Comparison of Effects of Abdominal Draw-In Lumbar Stabilization Exercises with and without Respiratory Resistance on Women with Low Back Pain: A Randomized Controlled Trial. Med Sci Monit. 2020;26:e921295. 
14. Sipaviciene S, Kliziene I. Effect of different exercise programs on non-specific chronic low back pain and disability in people who perform sedentary work. Clin Biomech (Bristol, Avon). 2020;73:17-27.

15. Shamsi MB, Rezaei M, Zamanlou M, Sadeghi M, Pourahmadi MR. Does core stability exercise improve lumbopelvic stability (through endurance tests) more than general exercise in chronic low back pain? A quasi-randomized controlled trial. Physiotherapy Theory and Practice. 2016 ;32(3):171178.

16. Koumantakis GA, Watson PJ, Oldham JA. Trunk muscle stabilization training plus general exercise versus general exercise only: randomized controlled trial of patients with recurrent low back pain. Phys Ther. 2005;85(3):209-225.

17. Moon HJ, Choi KH, Kim DH, et al. Effect of lumbar stabilization and dynamic lumbar strengthening exercises in patients with chronic low back pain. Ann Rehabil Med. 2013;37(1):110-117.

18. Hadała M, Gryckiewicz S. The effectiveness of lumbar extensor training: local stabilization or dynamic strengthening exercises. A review of literature. Ortop Traumatol Rehabil. 2014;16(6):561572. doi:10.5604/15093492.1135044

19. Sertpoyraz F, Eyigor S, Karapolat H, Capaci K, Kirazli Y. Comparison of isokinetic exercise versus standard exercise training in patients with chronic low back pain: a randomized controlled study. Clin Rehabil. 2009;23(3):238-247. doi:10.1177/0269215508099862.

20. Soukayna M, Hassane KE, Hassan K, Khodor HH. Patient's adherence to prescribed home exercises: Barriers and interventions. 2018;10.4238/gmr16039898.

21. Campbell R, Evans M, Tucker M, Quilty B, Dieppe P, Donovan JL. Why don't patients do their exercises? Understanding non-compliance with physiotherapy in patients with osteoarthritis of the knee. J Epidemiol Community Health. 2001;55(2):132-138. doi:10.1136/jech.55.2.132.

22. Engström LO, Oberg B. Patient adherence in an individualized rehabilitation programme: a clinical follow-up. Scand J Public Health. 2005;33(1):11-8.

23. Fjell AM, Walhovd KB. Structural Brain Changes in Aging: Courses, Causes and Cognitive Consequences. Reviews in the Neurosciences. 2010;21:187-221.

24. Peek K, Carey M, Mackenzie L, Sanson-Fisher R. Patient adherence to an exercise program for chronic low back pain measured by patient-report, physiotherapist-perception and observational data. Physiother Theory Pract. 2019;35(12):1304-1313.

\section{Tables}




\section{Table 1}

Duration, number of repetitions, and the extent of remembering. (Second=sec)

\begin{tabular}{|lllllll|} 
& $\begin{array}{l}\text { Duration of learning } \\
(\mathbf{s e c})\end{array}$ & $\begin{array}{l}\text { Repetitions of } \\
\text { learning }\end{array}$ & & \multicolumn{2}{c|}{ Remembering } & \multicolumn{2}{c|}{$\begin{array}{l}\text { Not- } \\
\text { remembering }\end{array}$} \\
\cline { 4 - 7 } & & & $\mathbf{n}$ & $\%$ & $\mathbf{n}$ & $\%$ \\
\hline $\begin{array}{l}\text { Hamstring } \\
\text { Stretch }\end{array}$ & $22.46 \pm 13.27$ & $2(1-3)$ & 54 & $78.2 \%$ & 15 & $21.8 \%$ \\
\hline $\begin{array}{l}\text { Anterior Pelvic } \\
\text { Tilt }\end{array}$ & $28.40 \pm 11.92$ & $4(1-5)$ & 42 & $60.8 \%$ & 27 & $39.2 \%$ \\
\hline $\begin{array}{l}\text { Posterior Pelvic } \\
\text { Tilt }\end{array}$ & $28.18 \pm 12.74$ & $4(1-5)$ & 43 & $62.3 \%$ & 26 & $37.7 \%$ \\
\hline Lumbar Stretch & $20.43 \pm 10.24$ & $3(1-4)$ & 64 & $92.7 \%$ & 5 & $7.3 \%$ \\
\hline Flexor Stretch & $20.55 \pm 10.71$ & $3(1-4)$ & 45 & $65.2 \%$ & 24 & $34.8 \%$ \\
\hline
\end{tabular}

\section{Table 2}

Extent of remembering compared with sociodemographic characteristics

\begin{tabular}{|llll|}
\hline & $\begin{array}{l}\text { Remember } \\
(\mathrm{n}=\mathbf{2 0})\end{array}$ & $\begin{array}{l}\text { Not-Remembering } \\
(\mathrm{n}=49)\end{array}$ & $\boldsymbol{p}$ \\
\hline Age (years) & $37.70 \pm 1.73$ & $50.38 \pm 1.52$ & 0.000 \\
\hline $\begin{array}{l}\text { Gender } \\
\quad \text { Female }\end{array}$ & 10 & 29 & 0.332 \\
$\quad$ Male & 10 & 20 & \\
\hline $\begin{array}{l}\text { Educational status } \\
\text { Lower than high school (48) }\end{array}$ & 8 & 40 & 0.000 \\
$\quad$ High school (10) & 3 & 7 & \\
$\quad$ University (11) & 9 & 2 & \\
\hline
\end{tabular}




\section{Table 3}

Comparison of patients durations of learning and their educational status.

\begin{tabular}{|c|c|c|c|c|}
\hline & $\begin{array}{l}\text { Lower Than High } \\
\text { School } \\
(n=48)\end{array}$ & $\begin{array}{l}\text { High School } \\
(n=10)\end{array}$ & $\begin{array}{l}\text { University } \\
(n=11)\end{array}$ & $\mathbf{p}$ \\
\hline & $\begin{array}{l}\text { Median } \\
\text { (minimum-maximum) }\end{array}$ & $\begin{array}{l}\text { Median } \\
\text { (minimum- } \\
\text { maximum) }\end{array}$ & $\begin{array}{l}\text { Median } \\
\text { (minimum- } \\
\text { maximum) }\end{array}$ & \\
\hline $\begin{array}{l}\text { Hamstring } \\
\text { stretch }\end{array}$ & $\begin{array}{l}20 \mathrm{sec} \\
(10-60)\end{array}$ & $\begin{array}{l}20 \mathrm{sec} \\
(10-60)\end{array}$ & $\begin{array}{l}10 \mathrm{sec} \\
(10-30)\end{array}$ & $0.004^{a}$ \\
\hline $\begin{array}{l}\text { Anterior pelvic } \\
\text { tilt }\end{array}$ & $\begin{array}{l}30 \mathrm{sec} \\
(10-60)\end{array}$ & $\begin{array}{l}25 \mathrm{sec} \\
(10-30)\end{array}$ & $\begin{array}{l}20 \mathrm{sec} \\
(10-30)\end{array}$ & $0.000^{b}$ \\
\hline $\begin{array}{l}\text { Posterior pelvic } \\
\text { tilt }\end{array}$ & $\begin{array}{l}30 \mathrm{sec} \\
(10-70)\end{array}$ & $\begin{array}{l}20 \mathrm{sec} \\
(10-30)\end{array}$ & $\begin{array}{l}20 \mathrm{sec} \\
(10-30)\end{array}$ & $0.000^{c}$ \\
\hline Lumbar stretch & $\begin{array}{l}20 \mathrm{sec} \\
(10-45)\end{array}$ & $\begin{array}{l}20 \mathrm{sec} \\
(10-60)\end{array}$ & $\begin{array}{l}15 \mathrm{sec} \\
(10-30)\end{array}$ & 0.372 \\
\hline Flexor stretch & $\begin{array}{l}20 \mathrm{sec} \\
(10-45)\end{array}$ & $\begin{array}{l}20 \mathrm{sec} \\
(10-60)\end{array}$ & $\begin{array}{l}10 \mathrm{sec} \\
(10-20)\end{array}$ & $0.004^{d}$ \\
\hline
\end{tabular}




\section{Table 4}

Comparison of patients, repetetions of learning and their educational status.

\begin{tabular}{lll}
$\begin{array}{l}\text { Lower Than High } \\
\text { School } \\
(\mathrm{n}=48)\end{array}$ & $\begin{array}{l}\text { High School } \\
(\mathrm{n}=10)\end{array}$ & $\begin{array}{l}\text { University } \\
(\mathrm{n}=11)\end{array}$ \\
\hline $\begin{array}{l}\text { Median } \\
\text { (minimum-maximum) }\end{array}$ & $\begin{array}{l}\text { Median } \\
\text { (minimum- } \\
\text { maximum) }\end{array}$ & $\begin{array}{l}\text { Median } \\
\text { (minimum- } \\
\text { maximum) }\end{array}$
\end{tabular}

\begin{tabular}{|c|c|c|c|c|}
\hline $\begin{array}{l}\text { Hamstring } \\
\text { stretch }\end{array}$ & $\begin{array}{l}2 \\
(1-3)\end{array}$ & $\begin{array}{l}2 \\
(1-3)\end{array}$ & $\begin{array}{l}1 \\
(1-3)\end{array}$ & 0.054 \\
\hline $\begin{array}{l}\text { Anterior pelvic } \\
\text { tilt }\end{array}$ & $\begin{array}{l}2 \\
(1-5)\end{array}$ & $\begin{array}{l}1 \\
(1-2)\end{array}$ & $\begin{array}{l}2 \\
(1-2)\end{array}$ & $0.000^{a}$ \\
\hline $\begin{array}{l}\text { Posterior pelvic } \\
\text { tilt }\end{array}$ & $\begin{array}{l}2 \\
(1-5)\end{array}$ & $\begin{array}{l}1 \\
(1-2)\end{array}$ & $\begin{array}{l}2 \\
(1-2)\end{array}$ & $0.001^{b}$ \\
\hline Lumbar stretch & $\begin{array}{l}2 \\
(1-4)\end{array}$ & $\begin{array}{l}1 \\
(1-2)\end{array}$ & $\begin{array}{l}1 \\
(1-2)\end{array}$ & 0.949 \\
\hline Flexor stretch & $\begin{array}{l}2 \\
(1-4)\end{array}$ & $\begin{array}{l}1 \\
(1-2)\end{array}$ & 1 & $0.006^{c}$ \\
\hline
\end{tabular}

a Lower Than High School and the other groups p:0.003, ${ }^{b}$ Lower Than High School and the other groups p:0.001, ${ }^{C}$ University and and the other groups p:0.006. 


\section{Table 5}

Comparison of patients, remember's and their educational status.

$\begin{array}{lll}\text { Lower Than High School } & \text { High School } & \text { University } \\ (n=48) & (n=10) & (n=11)\end{array}$

Remember\Not- Remember

\begin{tabular}{lllll|}
\hline Hamstring stretch & $37 \backslash 11$ & $8 \backslash 2$ & $9 \backslash 2$ & 0.713 \\
\hline Anterior pelvic tilt & $23 \backslash 25$ & $8 \backslash 2$ & $11 \backslash 0$ & $\mathbf{0 . 0 0 1}^{\mathrm{a}}$ \\
\hline Posterior pelvic tilt & $25 \backslash 23$ & $7 \backslash 3$ & $11 \backslash 0$ & $\mathbf{0 . 0 0 3}^{\mathrm{b}}$ \\
\hline Lumbar stretch & $43 \backslash 5$ & $10 \backslash 0$ & $11 \backslash 0$ & 0.156 \\
\hline Flexor stretch & $29 \backslash 19$ & $6 \backslash 4$ & $10 \backslash 1$ & 0.087
\end{tabular}

a Lower Than High School and University $p=0.003,{ }^{b}$ Lower Than High School and University $p=$ 0.008 . 